\title{
SCIDOC
}

\author{
International Journal of Dentistry and Oral Science (IJDOS) \\ ISSN: 2377-8075
}

\section{Evaluation of the Erosive Effect of Chewing Aspocid versus its Soluble Form on Micro Hardness of Primary Teeth Enamel in Heart Disease Children. (In Vitro-Study)}

Research Article

Bardis S. Abdelaziz ${ }^{1}$, Gehan G. Allam², Amr M. Abdel Aziz ${ }^{3}$

${ }^{1}$ Post-graduate student from Cairo University and Master Candidate in Department of Pediatric Dentistry and Dental Public Health, Faculty of Dentistry Ain Shams University. Cairo, Egypt.

${ }^{2}$ Pediatric Dentistry and Dental Public Health, Faculty of Dentistry Ain Shams University. Cairo, Egypt.

${ }^{3}$ Pediatric Dentistry and Dental Public Health Department, Faculty of Dentistry Ain Shams University. Cairo, Egypt.

\section{Abstract}

Background: Aspocid $75 \mathrm{mg}$ chewing tablets $(\mathrm{pH}=3)$ is the usual drug used in children with heart disease, this acidic medicine is available in Egyptian markets and accessible by the public. This may lead to increase their susceptibility to dental erosion.

Aim: The aim of this study was to compare the effect of chewing aspocid on the micro hardness of primary teeth and comparing with that of its soluble form.

Design: A total number of thirty six exfoliated primary teeth were randomly assigned to two groups after measuring micro hardness at base line: group(A) Exposed to chewing aspocid tablets under vibration to mimic the chewing process, group(B) Exposed to $100 \mathrm{ml}$ aspocid solution. All teeth were prepared for micro hardness test after acidic treatment.

Results: Microhardness decreased in both groups. However group (A) showed the highest reduction in its micro hardness values than group (B).

Conclusion: Aspocid caused reduction in enamel surface micro hardness in both groups.

Keywords: Aspocid; Erosion; Microhardness; Primary Teeth.

\section{Abbreviations: CHD: Congenital Heart Disease; RHD: Rheumatic Heart Disease; PVC: Polyvinyl Chloride; SD: Standard} Deviation.

\section{Introduction}

Heart disease is one of the most common developmental abnormalities among children, occurring in approximately 8 to 10 in 1,000 births. Heart diseases observed in children and adolescents are mainly congenital or acquired heart disease [1].

Many studies showed that, children with heart disease have higher prevalence of enamel hypoplasia, caries and erosion than normal children, and that could be due to many reasons such as their attitude and knowledge toward oral hygiene measures, sugary diet and medications that could increase their susceptibility to caries and erosion [2].

In addition that congenital heart disease (CHD)was accused to cause alteration in the structure of enamel and dentin of deciduous incisors, and significantly decrease in mineral content which also increase susceptibility to erosion $[3,4]$.

Children with heart diseases take aspocid in chewable tablets which comes in direct contact with their teeth especially occlusal surfaces and that increase their susceptibility to dental erosion, usual doses are $75-100 \mathrm{mg} / \mathrm{kg} /$ day divided on 4 doses for $2-6$ weeks to treat inflammation in children with rheumatic heart disease (RHD) and $5 \mathrm{mg} / \mathrm{kg} /$ day in single dose daily for life long to act as antiplatelet in children with congenital heart disease (CHD) [2].

Aspocid is available in the Egyptian markets and is accessible by the public. Each tablet contains about $75 \mathrm{mg}$ acetylsalicylic acid

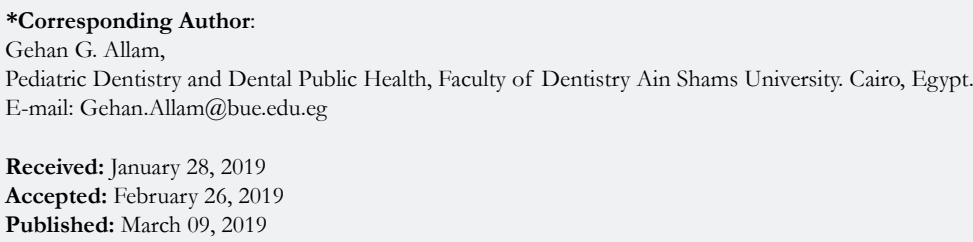

Citation: Bardis S. Abdelaziz, Gehan G. Allam, Amr M. Abdel Aziz. Evaluation of the Erosive Effect of Chewing Aspocid versus its Soluble Form on Micro Hardness of Primary Teeth Enamel in Heart Disease Children. (In Vitro-Study). Int J Dentistry Oral Sci. 2019;6(3):681-684. doi: http://dx.doi.org/10.19070/2377-8075-19000134

Copyright: Gehan G. Allam 2019. This is an open-access article distributed under the terms of the Creative Commons Attribution License, which permits unrestricted use, distribution and reproduction in any medium, provided the original author and source are credited. 
and its $\mathrm{pH}=3$.

This chronic administration of such acidic medications and which come in direct contact with teeth is identified as an extrinsic etiologic factor in dental erosion, not only for adults but also for children [4-6].

That's why this study was conducted to evaluate the effect of chewing aspocid on the micro hardness of primary teeth and comparing it with the effect of soluble form of aspocid.

\section{Materials and Methods}

A total number of thirty six primary teeth (18 in each group) is calculated using Epicalc program version 1.02 assuming a power of $80 \%$ and alpha $=0.05$. The sample size is based on Mean \pm SD of micro hardness before and after immersion in acidic medium was $331 \pm 16.2$ and $321 \pm 17.5$, respectively.

\section{Examination and Storage of Teeth}

A total of thirty six sound exfoliated human primary teeth were collected and thoroughly cleaned from gross debris using a polishing brush mounted in low speed hand-piece and a non-fluoride polishing paste. All teeth were thoroughly examined under the stereomicroscope (Olympus SZ-PT Japan stereo-light Microscope) to assure that they were free from caries, hypocalcification and cracking. Teeth were stored in artificial saliva from the time of collection until usage [7].

Each tablet of aspocid were dissolved in $100 \mathrm{~mL}$ of distilled water as no guidelines were given by the manufacturers on the volume of water required to dissolve the tablets [8].

\section{Preparation of Specimens}

Enamel specimens were mounted in the middle of acrylic mold with buccal surface facing upward [6]. The acrylic molds were constructed in a polyvinyl chloride (PVC) ring. The ring's dimensions were $25 \mathrm{~mm}$ in diameter, and $20 \mathrm{~mm}$ in depth [6]. Separating medium was painted to the ring. Cold cure acrylic resin material was then mixed according to manufacturer's instruction in a glass container, and packed into PVC ring using a spatula. The PVC ring was then placed on a glass slab to obtain a flat base [6]. Approaching the setting time of the acrylic resin, enamel specimens were fixed in the middle of the acrylic mold and facing upwards [6]. For standardization pink wax was cut into small squares of $3 \times 3 \mathrm{~mm}$ in dimensions, and placed over the enamel surfaces before the varnish application and then removed by using tweezers after hardening of varnish [7].

Microhardness testing was done at baseline [9]. Then teeth were divided randomly into two groups each $(n=18)$. First group was exposed to chewing aspirin tablet and artificial saliva, at room temperature, under vibration by (speed of $7200 \mathrm{vpm}$ ), and for five minutes 3 times/day during five days 3 to mimic the chewing process, Second group was exposed to $100 \mathrm{ml}$ aspirin solution for 3 min under constant shaking at $37^{3} 3$ times/day for five days [6].

After the acidic procedures, specimens were washed in distilled water for 20 seconds, individually, immersed in $10 \mathrm{ml}$ of artificial saliva, and stored until the next experimental step [3, 10]. At the end of the last step, specimens were stored in artificial saliva until the next day. In all groups, artificial saliva was changed daily [3]. At the end of the experimental period, specimens were submitted again to micro hardness test [11].

\section{Microhardness Testing}

Micro hardness was measured by using Vickers micro hardness tester machine (Yukon 1202, Wilson Hardness Tester, USA). Three indentations were carried out for each specimen at $25 \mathrm{~g}$ force for 30 seconds, the average score of three readings were recorded for each specimen [12-15].

\section{Results}

\section{Inter and Intragroup Comparison of Microhardness}

Mean, Standard deviation (SD) values for inter and intragroup comparison of micro hardness before and after acidic treatment were presented in table (1) and figures (2) and (3).

\section{Intergroup Comparison}

Before acidic treatment, group (I) had no significantly higher

Figure 1. Acrylic mold Fabrication.
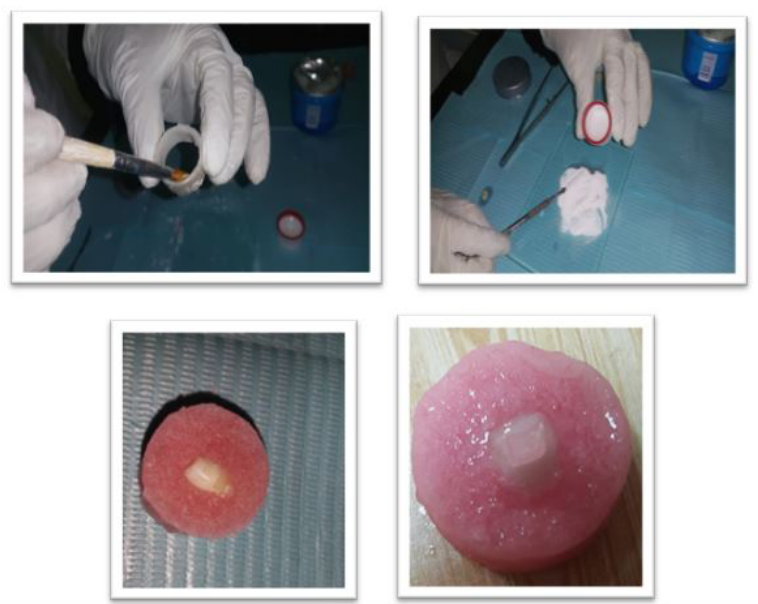
Table 1. Mean, Standard deviation (SD) values for Inter and intragroup comparison of microhardness before and after acidic treatment.

\begin{tabular}{|c|c|c|c|}
\hline \multirow{2}{*}{ Acidic treatment } & \multicolumn{2}{|c|}{ Microhardness (Mean \pm SD) } & \multirow{2}{*}{ P-value } \\
\cline { 2 - 3 } & Group (I) & Group (II) & \\
\hline Before & $356.72 \pm 9.89$ & $349.21 \pm 13.61$ & $0.176 \mathrm{~ns}$ \\
\hline After & $308.60 \pm 9.53$ & $320.41 \pm 11.14$ & $0.034^{*}$ \\
\hline P-value & $<0.001^{*}$ & $<0.001^{*}$ & \\
\hline
\end{tabular}

*; significant $(\mathrm{p} \leq 0.05)$ ns; non-significant $(\mathrm{p}>0.05)$

Figure 2. Bar chart showing average intergroup comparison of micro hardness.

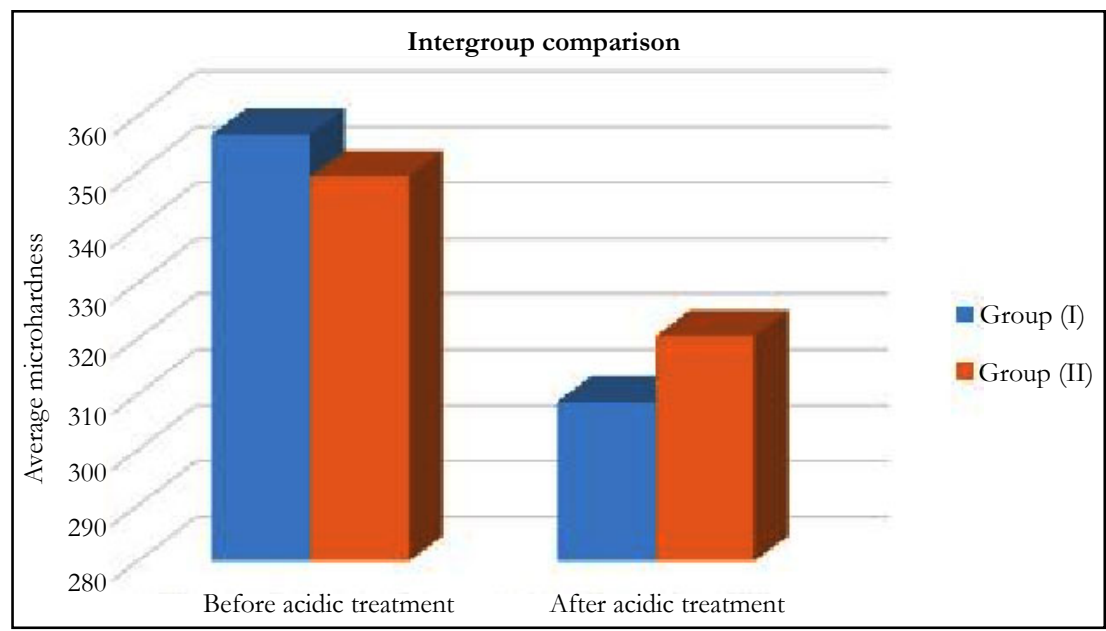

Figure 3. Bar chart showing average intragroup comparison of micro hardness.

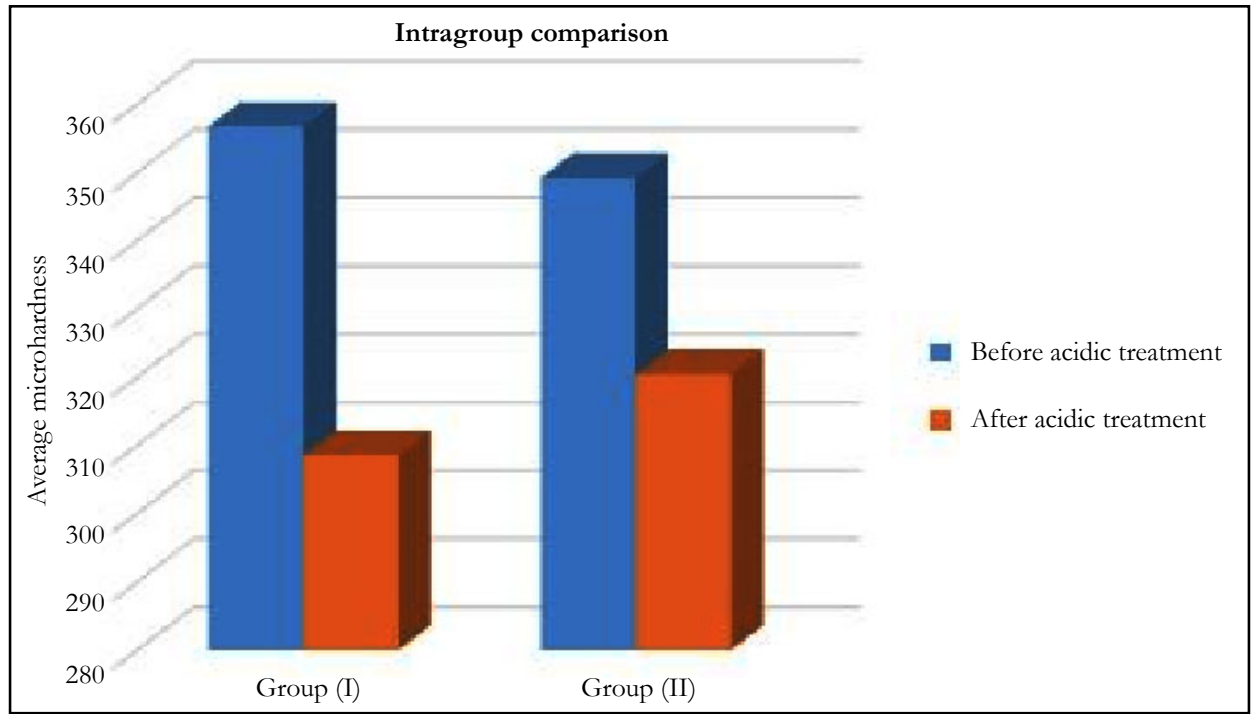

mean value than group (II), while after acidic treatment group (II) had a significantly higher mean value than group (I).

\section{Intragroup Comparison}

For both groups, micro hardness before acidic treatment had a significantly higher mean value than after acidic treatment.

\section{Discussion}

Children with heart disease require special attention from pediatric dentists, because these patients commonly have developmental enamel defects that increase their susceptibility to caries and erosion, in addition to their poor oral health $[16,17]$. The latter condition may be largely attributed to cardiac disease, whose attention and care may cause oral health to be underestimated and not given much importance $[18,19]$.

If dental erosionis not controlled and stabilized in such patients, they may suffer from severe tooth surface loss, tooth sensitivity, over closure, poor aesthetics, or even dental abscesses in the affected teeth [17].

Therefore, this in-vitro study aimed to assess the erosive effect of 
aspocid on primary teeth enamel in children with heart diseases and to determine the proper route of administration to control that erosive effect.

Aspocid $75 \mathrm{mg}$ chewing tablets were chosen, as this medicine is available in the Egyptian markets and accessible by the public. Each tablet of ASPOCID contains $75 \mathrm{mg}$ acetylsalicylic acid and its $\mathrm{pH}=3$.

We choose to assess enamel softening by measuring micro hardness according to Shelli's et al., [20].

In the present study, we used Vickers micro hardness testing to evaluate changes that occur after acidic treatment. Surface micro hardness evaluations was simple, fast, sensitive and easy to measure nondestructive methods by reflecting mineral changes that occurred due to different treatments. In addition, Vickers indenter is stated to be more accurate than knop indenter, as elongation of diagonal indentation leads to errors in hardness calculation [21].

Artificial saliva was used between the erosive immersion cycles to mimic the oral environment because of its proven ability to exert similar re mineralizing effect as that of fresh human saliva [21].

Our study showed that surface microhardness of teeth blocks exposed to ASPOCID aspirin solution decreased and that is consistent with systemic review by Zero T. (1996) [22].

This study proved that when primary teeth enamel exposed to chewing tablets of aspocid its surface micro hardness decreased more than when it exposed to aspirin solution and that was in agreement with the in vivo study that examined forty two children with rheumatoid arthritis, and showed that the children who chewed aspirin experienced severe erosion of the upper and lower primary molars, and in their permanent molars and children who swallowed the aspocid tablets experienced no erosion of their teeth [23].

On the contrary, this study was in disagreement with the in vitro study that carried out in the Department of Oral and Dental Science, University of Bristol, UK to evaluate and compare the erosive effect of some analgesics on human enamel and found that AlkaSeltzer TM, AnadinExtra TM and Aspro TM which are different types of aspirin cause no detectable erosion and that can be explained by the presence of remineralizing agents such as sodium bicarbonate, saccharin sodium, aspartame and mannitol [8]. While aspocid which is available in Egypt doesn't contain such remineralizing agents.

Why this paper is important to pediatric dentists:

- To give evidence of the effect of chewing aspocid on decreasing microhardness of enamel of primary teeth in order to spread awareness among pediatric cardiologists, children suffering from heart disease and their parents

- More efforts for erosion prevention must be directed towards CHD children, especially those in developing countries as they are at higher risk.

- Increase cooperation between pediatric dentists and pediatric cardiologists in order to be able to prescribe soluble form of aspocid instead of chewable tablets.

\section{References}

[1]. Mc Crindle BW. Cardiovascular consequences of paediatric obesity: Will there be a future epidemic of premature cardiovascular disease?. Paediatr Child Health. 2007 Mar;12(3):175-7. PubMed PMID: 19030355.

[2]. Thornley S, Sundborn G, Schmidt-Uili SM. Rheumatic fever in New Zealand: what are the teeth trying to tell us? Pac Health Dialog. 2014 Mar;20(1):7-10. PubMed PMID: 25928989.

[3]. Wichman CL, Moore KM, Lang TR, Sauver JL, Heise Jr RH, Watson WJ. Congenital heart disease associated with selective serotonin reuptake inhibitor use during pregnancy. Mayo Clin Proc. 2009;84(1):23-7. PubMed PMID: 19121250.

[4]. El-Hawary YM, El-Sayed B, Abd-Alhakem G, Ibrahim FM. Deciduous teeth structure changes in congenital heart disease: Ultrastructure and microanalysis. Interv Med Appl Sci. 2014 Sep;6(3):111-7. doi: 10.1556/ IMAS.6.2014.3.3. PubMed PMID: 25243076.

[5]. Abhinay C, Shweta C, Jay C, Aditi J, Puneet G, Priyanka T. Indices for measuring dental erosion. Chatti J Of Health Sciences. 2013;1:35-46.

[6]. Lussi A, Kohler N, Zero D, Schaffner M, Megert B. A comparison of the erosive potential of different beverages in primary and permanent teeth using an in vitro model. Eur J Oral Sci. 2000 Apr;108(2):110-4. PubMed PMID: 10768723.

[7]. Pani SC, Alenazi FM, Alotain AM, Alanazi HD, Alasmari AS. Extrinsic tooth staining potential of high dose and sustained release iron syrups on primary teeth. BMC Oral Health. 2015 Aug 4;15:90. doi: 10.1186/s12903015-0072-0. PubMed PMID: 26238197.

[8]. McNally LM, Barbour ME, O'Sullivan DJ, Jagger DC. An in vitro investigation of the effect of some analgesics on human enamel. J Oral Rehabil. 2006 Jul;33(7):529-32. PubMed PMID: 16774512.

[9]. Sundaram G, Bartlett D. Preventative measures for bulimic patients with dental erosion. Eur J Prosthodont Restor Dent. 2001 Mar;9(1):25-9. PubMed PMID: 11695131.

[10]. Valena V, Young WG. Dental erosion patterns from intrinsic acid regurgitation and vomiting. Aust Dent J. 2002 Jun;47(2):106-15. PubMed PMID: 12139263.

[11]. Asher C, Read MJ. Early enamel erosion in children associated with the excessive consumption of citric acid. Br Dent J. 1987 May 23;162(10):384-7. PubMed PMID: 3472545.

[12]. Scatena C, Galafassi D, Gomes-Silva JM, Borsatto MC, Serra MC. In vitro erosive effect of pediatric medicines on deciduous tooth enamel. Braz Dent J. 2014 Jan-Feb;25(1):22-7. PubMed PMID: 24789287.

[13]. Hunter ML, Hughes JA, Parker DM, West NX, Newcombe RG, Addy M. Development of low erosive carbonated fruit drinks. 1. Evaluation of two experimental orange drinks in vitro and in situ. J Dent. 2003 May;31(4):25360. PubMed PMID: 12735919.

[14]. Ganss C, Klimek J, Schwarz N. A comparative profilometric in vitro study of the susceptibility of polished and natural human enamel and dentine surfaces to erosive demineralization. Arch Oral Biol. 2000 Oct;45(10):897-902. PubMed PMID: 10973563.

[15]. Barbour ME, Parker DM, Allen GC, Jandt KD. Human enamel dissolution in citric acid as a function of $\mathrm{pH}$ in the range $2.30 \leq \mathrm{pH} \leq 6.30-\mathrm{a}$ nanoindentation study. Eur J Oral Sci. 2003 Jun;111(3):258-62. PubMed PMID: 12786958.

[16]. Al-Dlaigan YH, Shaw L, Smith AJ. Is there a relationship between asthma and dental erosion? A case control study. Int J Paediatr Dent. 2002 May;12(3):189-200. PubMed PMID: 12028311.

[17]. O'Brien M. Children's dental health in the United Kingdom 1993. HMSO; 1994.

[18]. Pimentel EL, Azevedo VM, Castro Rde A, Reis LC, De Lorenzo A. Caries experience in young children with congenital heart disease in a developing country. Braz Oral Res. 2013 Mar-Apr;27(2):103-8. PubMed PMID: 23538422.

[19]. Da Silva DB, Souza IP, Cunha MC. Knowledge, attitudes and status of oral health in children at risk for infective endocarditis. Int J Paediatr Dent. 2002 Mar;12(2):124-31. PubMed PMID: 11966890.

[20]. Shellis RP, Ganss C, Ren Y, Zero DT, Lussi A. Methodology and models in erosion research: discussion and conclusions. Caries Res. 2011;45 Suppl 1:69-77. doi: 10.1159/000325971. PubMed PMID: 21625135.

[21]. Hara AT, Ando M, Gonzalez-Cabezas C, Cury JA, Serra MC, Zero DT. Protective effect of the dental pellicle against erosive challenges in situ. J Dent Res. 2006 Jul;85(7):612-6. PubMed PMID: 16798860.

[22]. Zero DT. Etiology of dental erosion-extrinsic factors. Eur J Oral Sci. 1996 Apr;104(2 ( Pt 2)):162-77. PubMed PMID: 8804884.

[23]. Sullivan RE, Kramer WS. Iatrogenic erosion of teeth. ASDC J Dent Child. 1983 May-Jun;50(3):192-6. PubMed PMID: 6575988. 